DOI: $10.15690 /$ vramn569

А.В. Лазарева, О.А. Крыжановская, Ю.А. Бочарова, И.В. Чеботарь, Н.А. Маянский

Научный центр здоровья детей Минздрава России, Москва, Российская Федерация

\title{
Распространенность
}

\section{металло- $\beta$-лактамаз и эффлюкс-механизмов} у карбапенемрезистентных госпитальных штаммов Pseudomonas aeruginosa, выделенных в г. Москве в 2012-2015 гг.

\begin{abstract}
Обоснование. Синегнойная палочка - Pseиdoтопаs aeruginosa - входит в число наиболее актуальных возбудителей оппортунистических инфекций, являясь одной из главных причин госпитальной заболеваемости. Цель: проанализировать роль металло- $\beta$-лактамаз (МБЛ) и эффлюкс-механизмов в формировании карбапенемрезистентности у госпитальных штаммов Р. аегиginоsа. Методы. В качестве объектов исследования были использованы 54 изолята P. aеruginosa от детей и взрослых пациентов из трех госпиталей города Москвы, полученных в течение 2012-2015 г2. Для всех штаммов были определены минимальные подавляющие концентрации (МПК) меропенема. Все отобранные штаммы были протестированы на наличие МБЛ путем подавления их активности этилендиаминтетрауксусной кислотой. Оценка активности эффлюкс-систем производилась на основе определения степени подавления МПК под влиянием ингибитора эффлюкса карбонил-цианид-3-хлорфенилгидразона. Результаты. Было выявлено 69\% (37/54) МБЛ-продуцирующих штаммов [МБЛ(+)], значимость эффлюкс-механизмов в формировании карбапенемрезистентности подтверждена у 54\% (29/54) штаммов. В 19\% (10/54) карбапенемрезистентных изолятов Р. аегияіпоsа не обнаружено ни МБЛ, ни активности эффлюкс-систем. Распространенность МБЛ положительно коррелировала $\left(r^{S}=0,068\right)$ с активностью эффлюкса: среди бактерий с отсутствием эффлюкс-активности было 60\% МБЛ(+)-штаммов, среди изолятов с умеренным эффлюксом - 74\%, а в популяции с гиперэкспрессией эффлюкса 83\% штаммов обладали МБЛ. Заключение. Полученные результаты иллюстрируют широкую распространенность важнейших механизмов карбапенемрезистентности - МБЛ- и эффлюкс-активности - и доказывают существование сложных сочетаний различных форм устойчивости у одного и того же штамма. Полученная информация может быть полезной для создания лечебно-профилактических методов борьбы с карбапенемрезистентностью.
\end{abstract}

Ключевые слова: Pseudomonas aеruginosa, антибиотикорезистентность, карбапенемы, эффлюкс, металло-ß-лактамазы.

(Для цитирования: Лазарева А.В., Крыжановская О.А., Бочарова Ю.А., Чеботарь И.В., Маянский Н.А. Распространенность металло- $\beta$-лактамаз и эффлюкс-механизмов у карбапенемрезистентных госпитальных штаммов Pseudomonas aeruginosa, выделенных в г. Москве в 2012-2015 гг. Вестник РАМH. 2015; 70 (6): 679-683. Doi: 10.15690/vramn569)

A.V. Lazareva, O.A. Kryzhanovskaya, Yu.A. Bocharova, I.V. Chebotar', N.A. Mayanskiy Scientific Centre of Children Health, Moscow, Russian Federation

\section{The Prevalence of Metallo- $\beta$-Lactamases and Efflux-Mediated Mechanisms in Carbapenem Nonsusceptible Nosocomial Pseudomonas aeruginosa Isolated in Moscow in 2012-2015}

Background. Pseudomonas aeruginosa, the major nosocomial opportunistic pathogen, is an important cause of infectious morbidity and mortality among immunocompromised patients. Objective. To establish the role of metallo- $\beta$-lactamases (MBL) and efflux-mediated mechanisms in conferring carbapenem resistance in nosocomial isolates of $P$. aeruginosa. Methods. We analyzed carbapenem nonsusceptible nosocomial P. aeruginosa isolates obtained from pediatric and adult patients at three hospitals in Moscow in 2012-2015. Carbapenem susceptibility was assessed using the E-test. In addition, minimal inhibitory concentrations (MICs) of meropenem were tested by the broth microdilution method. The presence of MBL was determined using the EDTA-mediated suppression test. Efflux-dependent resistance was measured using an assay based on MIC modification by an ionophore carbonyl cyanide 3-chlorophenyl hydrazine (CCCP). Results. A total of 54 carbapenem nonsusceptible P. aeruginosa isolates was examined. The presence of an MBL was detected in 37 (69\%) isolates, 29 (54\%) isolates had efflux-mediated resistance. In 10 (19\%) isolates neither MBL nor efflux activity was found. Five out of 6 isolates (83\%) with highly active efflux were MBL-positive. Among isolates with low efflux activity, 74\% (17/23) possessed MBL, whereas in isolates with no efflux the rate of MBL-positivity was $60 \%$ (15/25). Conclusion. The prevalence of MBL-and efflux-mediated carbapenem resistance in nosocomial P. aeruginosa is high. Moreover, our results reveal that several resistance mechanisms may combine at the isolate level. These data may contribute to the development of novel strategies in combating carbapenem resistance. Key words: Pseudomonas aeruginosa, antibiotic resistance, carbapenems, efflux, metallo- $\beta$-lactamases.

(For citation: Lazareva A.V., Kryzhanovskaya O.A., Bocharova Yu.A., Chebotar' I.V., Mayanskiy N.A. The Prevalence of Metallo- $\beta$ Lactamases and Efflux-Mediated Mechanisms in Carbapenem Nonsusceptible Nosocomial Pseudomonas Aeruginosa Isolated in Moscow in 2012-2015. Vestnik Rossiiskoi Akademii Meditsinskikh Nauk = Annals of the Russian Academy of Medical Sciences. $2015 ; 70$ (6): $679-683$. Doi: $10.15690 /$ vramn569) 


\section{Обоснование}

Патологические процессы, ассоциированные с Pseudomonas aeruginosa, занимают одно из ведущих мест в структуре инфекционной заболеваемости $[1,2]$. В России доля $P$. aeruginosa среди всех возбудителей бактериальных нозокомиальных инфекций составляет более $20 \%$ [3]. Одним из самых негативных свойств $P$. $a e-$ ruginosa является способность быстро адаптироваться к антибиотикам. Около $60 \%$ госпитальных штаммов синегнойной палочки резистентны к антисинегнойным цефалоспоринам - цефепиму и цефтазидиму, почти $70 \%$ - к пиперациллину/тазобактаму; к имипенему и меропенему устойчивы 88,0 и $66,8 \%$ изолятов $P$. aeruginosa, соответственно [3]. Главные механизмы резистентности синегнойной палочки связаны с ферментзависимым разрушением антибиотика, нарушением транспорта антибиотика внутрь клетки через мембранные порины и активацией выведения (эффлюкс) препарата из клетки во внешнюю среду [4]. В связи с особой опасностью пристальное внимание клиницистов привлекают изоляты, которые резистентны к антисинегнойным карбапенемам - меропенему, имипенему и дорипенему. Большинство публикаций о карбапенемрезистентности $P$. aeruginosa базируется только на фенотипической регистрации этого феномена диско-диффузионным способом, с помощью Е-тестов либо на бактериологических анализаторах Vitek, Phoenix и др. [5]. Во многих работах регистрация карбапенемрезистентности сочетается с попыткой объяснить ее возникновение с позиции лишь одного из механизмов - выработки специальных $\beta$-лактамаз, которые получили название карбапенемазы $[6,7]$. Наиболее активные карбапенемазы относятся к группе металло- $\beta$-лактамаз (МБЛ) [8]. В отечественной литературе практически отсутствуют публикации, посвященные изучению эффлюкс-механизмов и их вклада в формирование карбапенемрезистентности. Вместе с тем информация обо всех возможных механизмах карбапенемрезистентности может оказаться крайне важной для разработки новых лечебных подходов, которые позволят преодолеть барьер устойчивости P. aeruginosa $\mathrm{K}$ этой группе антибиотиков.

Цель настоящей работы - проанализировать роль металло- $\beta$-лактамаз и эффлюкс-механизмов в формировании карбапенемрезистентности у госпитальных штаммов $P$. aeruginosa.

\section{Методы}

\section{Дизайн исследования}

Работа проводилась по типу исследования серии случаев.

\section{Критерии соответствия}

Включение изолятов $P$. aeruginosa в исследование проводилось на основе критерия нечувствительности к карбапенемам, который определялся диско-диффузионным способом согласно современным требованиям $[9,10]$. При оценке чувствительности использовали терминологию Европейского комитета по тестированию чувствительности к антибиотикам (European Committee on Antimicrobial Susceptibility Testing, EUCAST), описывая штаммы как «резистентные» (resistant), «чувствительные» (susceptible) или штаммы с промежуточной чувствительностью (intermediate, or no fully susceptible isolates exist) [10].

\section{Описание эксперимента}

Исследование включало пять последовательных этапов:

1) отбор клинических изолятов $P$. aeruginosa;

2) тестирование изолятов $P$. aeruginosa на наличие МБЛ;

3) определение для отобранных изолятов минимальных подавляющих концентраций (МПК) меропенема и оценка их эффлюкс-активности;

4) статистическая обработка полученных результатов;

5) формально-логический анализ полученных результатов.

\section{Условия проведения исследования и методы регистрации результатов}

Bce отобранные штаммы были протестированы на наличие МБЛ согласно методике подавления активности МБЛ этилендиаминтетрауксусной кислотой (ЭДТА) [11]. Для всех штаммов были определены МПК меропенема в диапазоне двукратных разведений, содержащих от 0,5 до 8192 мкг/мл этого антибиотика [12]. Критерий МПК50 подразумевал значение МПК для 50\% исследованных штаммов, МПК90 - для 90\%. Для оценки активности эффлюкс-систем в 96-луночном планшете проводили определение МПК меропенема в присутствии ионофоpa карбонил-цианид-3-хлорфенилгидразона (Carbonyl Cyanide 3-Chlorophenylhydrazone, CCCP) в конечной концентрации 25 мкг/мл. Для этого СССР добавляли к культуре синегнойной палочки в бульоне Мюллера-Хинтона (0,5 ед. по МакФарланду), содержащей указанные выше разведения меропенема. В качестве контроля использовали пробы без добавления СССР. Об активности эффлюкса судили по отношению (кратности уменьшения, КУ) МПК меропенема в культурах без СССР к МПК при его добавлении. При величине КУ $<4$ регистрировали отсутствие эффлюкса, при КУ в диапазоне от 4 до 16 - умеренную активность, при КУ $>16$ - его высокую активность. В целом КУ $\geqslant 4$ расценивался как критерий эффлюкса, значимый для формирования карбапенемрезистентности [13].

Каждый штамм исследовали трехкратно в двух повторах.

\section{Этическая экспертиза}

Авторы декларируют, что в настоящем исследовании не проводилась работа с историями болезней, а также не использовались ткани человеческого организма либо животные ткани.

\section{Статистический анализ}

Статистическая обработка результатов выполнена при помощи программного пакета Statistica 6.0. Сравнение МПК проводили с помощью критерия Краскелла-Уоллиса с последующим попарным сравнением методом Манна-Уитни, корреляции оценивались помощью коэффициента Спирмена.

\section{Результаты}

\section{Участники исследования}

В качестве объекта исследования были использованы 54 карбапенемрезистентных изолята P. aeruginosa от детей и взрослых пациентов из трех лечебно-профилактических учреждений г. Москвы, полученные в течение 2012-2015 гг. МПК меропенема исследованных штаммов варьировали в диапазоне от 8 до 4096 мкг/мл (рис.), МПК50 составила 512 мкг/мл, МПК90 - 2048 мкг/мл. 


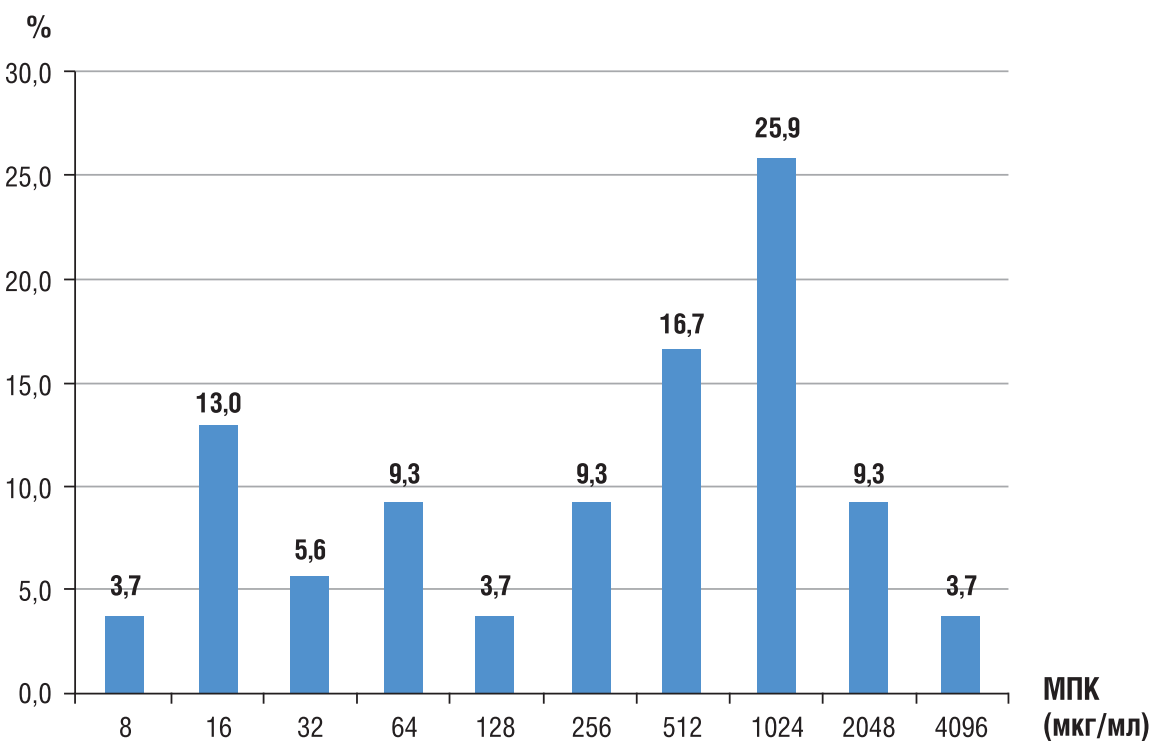

Рис. Распределение значений минимальных подавляющих концентраций (МПК) меропенема у исследованных карбапенемрезистентных штаммов $P$. aeruginosa $(\mathrm{n}=54)$

Примечание. По оси абсцисс - значения МПК меропенема (мкг/мл), по оси ординат - доля штаммов (\%) с конкретным значением МПК.

\section{Основные результаты исследования}

Тест ЭДТА-зависимого подавления карбапенемазной активности выявил наличие МБЛ у 37 (69\%) штаммов. У 29 (54\%) штаммов под влиянием СССР наблюдалось уменьшение МПК в 4 и более раз, что свидетельствовало о наличии активного эффлюкса [эффлюкс(+)-штаммы]. У штаммов обнаружены различные сочетания продукции МБЛ и их эффлюкс-активности (табл. 1). Самым распространенным оказался вариант сочетания МБЛ(+) и эффлюкс(+): он встречался у 22 (41\%) исследованных штаммов. Еще 15 (28\%) штаммов обладали МБЛ, но не проявляли эффлюкс-активности. В 7 (13\%) случаях регистрировался активный эффлюкс без продукции МБЛ. У 10 (19\%) изолятов не было обнаружено ни МБЛ, ни активности эффлюкс-систем. Медианы (Ме) МПК всех перечисленных групп не отличались между собой (во всех случаях $p>0,05$ ): в этих группах не было обнаружено корреляций между значениями МПК и наличием эффлюкса либо продукцией МБЛ.

\section{Дополнительные результаты исследования}

У эффлюкс(+)-штаммов КУ колебалась в диапазоне от 4 до 512 раз с Ме $4(4 ; 16)$. В таблице показаны выраженность активации выведения препарата из клетки во внешнюю среду, значения МПК меропенема и наличие МБЛ у карбапенемрезистентных штаммов $P$. aeruginosa. У 25 штаммов (46\%) эффлюкс меропенема отсутствовал; умеренный уровень наблюдался у 23 (43\%); 6 штаммов (11\%) с КУ >16 были отнесены к группе с гиперактивным эффлюксом, в которой КУ варьировал в диапазоне от 64 до 512 раз. Ме МПК меропенема в группах с отсутствием эффлюкса или с его низким уровнем отличались между собой статистически незначимо $(\mathrm{p}=0,093)$, но были значимо ниже значений МПК меропенема для группы штаммов с гиперактивностью эффлюкса $(\mathrm{p}=0,022)$. Интересно, что процент распространения МБЛ имел положительную корреляцию (средний уровень корреляции, коэффициент корреляции Спирмена $\left.-\mathrm{r}^{\mathrm{S}}=0,068\right)$ с уровнем активности эффлюкса: среди бактерий с отсутствием эффлюкс-активности было 60\% МБЛ-продуцирующих штаммов, среди изолятов с умеренным эффлюксом - 74\%, а в популяции с гиперэкспрессией $-83 \%$ (5 из 6 штаммов оказались МБЛ-положительными). И, наоборот, процент МБЛотрицательных штаммов уменьшался по мере нарастания активности эффлюкса.

\section{Обсуждение}

\section{Резюме основного результата исследования}

Важнейшими находками настоящего исследования были штаммы с высокими значениями МПК меропенема до 4096 мкг/мл, значительный процент распространенно-

Таблица 1. Активность эффлюкс-помп и значения МПК меропенема у МБЛ-позитивных и МБЛ-негативных штаммов P. aeruginosa

\begin{tabular}{|c|c|c|c|c|c|c|}
\hline \multirow{3}{*}{ № } & \multirow{3}{*}{$\begin{array}{l}\text { Активность } \\
\text { эффлюкса }\end{array}$} & \multirow{3}{*}{$\begin{array}{c}n \\
(\%)\end{array}$} & \multirow{2}{*}{\multicolumn{2}{|c|}{$\begin{array}{c}\text { МБЛ } \\
\text { Есть }\end{array}$}} & \multirow{2}{*}{\multicolumn{2}{|c|}{$\begin{array}{c}\text { МБЛ } \\
\text { Нет }\end{array}$}} \\
\hline & & & & & & \\
\hline & & & $\begin{array}{l}n \\
(\%)\end{array}$ & $\begin{array}{c}\text { МПК меропенема, мкг/мл; } \\
\text { Ме }(25 ; 75)\end{array}$ & $\begin{array}{c}n \\
(\%)\end{array}$ & $\begin{array}{l}\text { МПК меропенема, мкг/мл; } \\
\text { Ме }(25 ; 75)\end{array}$ \\
\hline 1 & $\begin{array}{l}\text { Отсутствует } \\
(\mathrm{KУ} \mathrm{<4)}\end{array}$ & $25(46)$ & $15 / 25(60)$ & $256(32 ; 1024)^{1}$ & $10 / 25(40)$ & $512(512 ; 1024)$ \\
\hline 2 & $\begin{array}{l}\text { Умеренная } \\
(4 \geqslant \mathrm{KУ} \leqslant 16)\end{array}$ & $23(43)$ & $17 / 23(74)$ & $128(64 ; 512)^{2}$ & $6 / 23(20)$ & $1024(512 ; 1024)$ \\
\hline 3 & $\begin{array}{l}\text { Высокая } \\
(\mathrm{KУ}>16)\end{array}$ & $6(11)$ & $5 / 6(83)$ & $2048(1024 ; 2048)^{3}$ & $1 / 6(17)$ & 4096 \\
\hline
\end{tabular}

Примечание. МПК - минимальные подавляющие концентрации, МБЛ - металло- $\beta$-лактамаза, КУ - кратность уменьшения. 1 vs 2 - статистически незначимые различия $(\mathrm{p}=0,093) ; 1$ vs 3 - статистически значимые различия ( $\mathrm{p}=0,017) ; 2$ vs $3-$ статистически значимые различия $(\mathrm{p}=0,022)$. 
сти МБЛ-позитивных (почти 70\%) и эффлюкс-активных (54\%) штаммов. Продукция МБЛ и эффлюкс-активность встречались в различных сочетаниях.

\section{Обсуждение основного результата исследования}

Данные о больших величинах МПК (до 4096 мкг/ мл) для исследованных штаммов отличаются от результатов, полученных при широкомасштабном изучении госпитальных изолятов синегнойной палочки в России, Беларуси и Казахстане (2002-2010 гг.) [14]. В этом исследовании максимальные значения МПК меропенема для МБЛ-позитивных штаммов составили 128 мкг/ мл. Различие результатов может объясняться методикой оценки МПК. M.V. Edelstein и соавт. оценивали МПК, используя метод разведений антибиотиков в агаре (agar dilution method), который имеет ряд ограничений [14]. В настоящей работе МПК определялась более точным способом серийных разведений в бульоне. Высокие значения МПК нередко выявляются для современных госпитальных штаммов P. aeruginosa: в работе W. Zhaо и соавт. все госпитальные штаммы, несущие ген $b l a$ IмР-10, имели МПК 4096 мкг/мл и более [15].

Высокий уровень распространенности штаммов, продуцирующих МБЛ, не является особенным. Полученные в настоящей работе данные сходны с результатами исследования M.A. Al-Kabsi и соавт., которые обнаружили среди госпитальных карбапенемрезистентных изолятов 63\% МБЛ-продуцирующих штаммов [16]. Такой большой процент МБЛ-штаммов среди карбапенемрезистентной популяции синегнойной палочки еще раз подтверждает исключительную значимость МБЛ в эволюции устойчивости бактерий к карбапенемам. Но, к сожалению, арсенал антикарбапенемных механизмов $P$. aeruginosa не исчерпывается только лактамазами, а определяется и другими механизмами [17]. В нашем исследовании почти у $54 \%$ исследованных изолятов было обнаружено значимое (в 4 раза и более) СССР-зависимое снижение МПК. Известно, что наиболее активное выведение $\beta$-лактамов из цитоплазмы синегнойной палочки реализуется через эффлюкс-системы МexCD-OprJ и MexAB-OprM, работа которых ингибируется в присутствии СССР [18, 19]. Следовательно, полученные нами результаты свидетельствуют о том, что более чем у половины изученных штаммов формирование карбапенемрезистентности происходило с участием эффлюкс-помп. Нередко у бактерий одного штамма выявляется сочетание нескольких механизмов карбапенемрезистентности [15]. Прямые доказательства присутствия сочетанных механизмов следуют из анализа комбинаций МБЛ и эффлюкс-активности у конкретных штаммов. Около $40 \%$ изолятов продуцировали МБЛ и проявляли эффлюкс-активность одновременно. Данные соответствуют результатам, полученным в других лабораториях [20].

Наиболее интригующей выглядела группа карбапенемрезистентных штаммов (19\%), у которых не было обнаружено ни МБЛ, ни эффлюкса. Вероятное объяснение этого феномена связано с альтернативными механизмами формирования резистентности, оценка которых не входила в задачи настоящего исследования. Многочисленные работы иллюстрируют возможность развития устойчивости, обусловленной сериновыми карбапенемазами (например, ОХА-группа $\beta$-лактамаз), которые не ингибируются в присутствии ЭДТА [21]. Карбапенемрезистентность может быть следствием блокады поринопосредованного поступления карбапенема в цитоплазму бактерии [22]. Отсутствие корреляций между значениями МПК и наличием МБЛ не позволяет оценить вклад, который вносят эти механизмы в количественные показатели резистентности. Причина отсутствия корреляции может крыться в других, нерасшифрованных в настоящем исследовании механизмах устойчивости к карбапенемам. Интересной находкой была позитивная корреляция между уровнем эффлюксактивности и распространенностью МБЛ. Это говорит о том, что два исследованных механизма резистентности могут работать в синергизме, вызывая рост ингибирующих концентраций карбапенемов до недостижимых в организме больного концентраций.

\section{Заключение}

Полученные результаты не только иллюстрируют распространенность важнейших механизмов карбапенемрезистентности - металло- $\beta$-лактамазной и эффлюксмеханизмов, но и доказывают существование сложных сочетаний различных вариантов устойчивости у одного и того же штамма. Около $40 \%$ карбапенемрезистентных нозокомиальных изолятов синегнойной палочки имеют комбинацию МБЛ-продукции и эффлюкс-механизмов, а у $19 \%$ штаммов карбапенемрезистентность не зависит ни от МБЛ, ни от эффлюкс-систем. Полученная информация может быть полезной для создания лечебно-профилактических методов борьбы с карбапенемрезистентностью.

\section{Источник финансирования}

Работа выполнена при финансовой поддержке Министерства образования и науки РФ (соглашение № 14.607.21.0064, уникальный идентификатор прикладных научных исследований RFMEFI60714X0064).

\section{Конфликт интересов}

Авторы статьи подтвердили отсутствие конфликта интересов, о котором необходимо сообщить.

\section{ЛИТЕРАТУРА}

1. Руднов ВА, Бельский ДВ, Дехнич АВ. Инфекции в ОРИТ России: результаты национального многоцентрового исследования. Клиническая микробиология и антимикробная химиотерапия. 2011;13(4):294-304.

2. Custovic A, Smajlovic J, Hadzic S, Ahmetagic S, Tihic N, Hadzagic H. Epidemiological surveillance of bacterial nosocomial infections in the surgical intensive care unit. Materia socio-medica. 2014;26 (1):7-11. doi: 10.5455/msm.2014.26.7-11

3. Сухорукова МВ, Эйдельштейн МВ, Склеенова ЕЮ, Иванчик НВ, Тимохова АВ, Шек ЕА, Дехнич АВ, Козлов РС.
Антибиотикорезистентность нозокомиальных штаммов Pseudomonas aeruginosa в стационарах России. Результаты многоцентрового эпидемиологического исследования МАРАФОН в 2011-2012 гг. Клиническая микробиология и антимикробная химиотерапия. 2014;16(4):273-279.

4. Страчунский ЛС, Белоусов ЮБ, Козлов СН. Практическое руководство по антиинфекционной химиотерапии. Смоленск: НИИАХ СГМА. 2002. 586 c.

5. Fritsche TR, Sader HS, Toleman MA, Walsh TR, Jones RN. Emerging metallo- $\beta$-lactamase mediated resistances: a summary 
report from the worldwide SENTRY antimicrobial surveillance program. Clin Infect Dis. 2005;41(Suppl.4):276-278.

6. Cornaglia G, Akova M, Amicosante G, Cantón R, Cauda R, Docquier JD, Edelstein M, Frère JM, Fuzi M, Galleni M, Giamarellou H, Gniadkowski M, Koncan R, Libisch B, Luzzaro F, Miriagou V, Navarro F, Nordmann P, Pagani L, Peixe L, Poirel L, Souli M, Tacconelli E, Vatopoulos A, Rossolini GM. Metallo-betalactamases as emerging resistance determinants in Gram negative pathogens: open issues. Int J Antimicrob Agents. 2007;29(4):380888. doi: 10.1016/j.ijantimicag.2006.10.008

7. Hrabák J, Cervená D, Izdebski R, Duljasz W, Gniadkowski M, Fridrichová M, Urbásková $\mathrm{P}$, Zemlicková $\mathrm{H}$. Regional spread of Pseudomonas aeruginosa ST357 producing IMP-7 metallo- $\beta$ lactamase in Central Europe. J Clin Microbiol. 2011;49(1):474-475. doi: 10.1128/JCM.00684-10

8. Hong DJ, Bae IK, Jang IH, Jeong SH, Kang HK, Lee K. Epidemiology and characteristics of metallo- $\beta$-lactamase producing Pseudomonas aeruginosa. Infect Chemother. 2015;47(2):81-97. doi: $10.3947 /$ ic. 2015.47 .2 .81

9. Определение чувствительности микроорганизмов к антимикробным препаратам. Государственное санитарно-эпидемиологическое нормирование Российской Федерации. Клинические рекомендации. М. 2014.

10. EUCAST Clinical breakpoints bacteria. URL: http://www.eucast. org. (Available: 14.11.2015).

11. Шевченко ОВ, Эйдельштейн МВ, Степанова МН. Металло- $\beta$-лактамазы: значение и методы выявления у грамотрицательных неферментирующих бактерий. Клиническая микробиология и антимикробная химиотерапия. 2007;1:211-218.

12. ГОСТ Р ИСО 20776-1-2010. Клинические лабораторные исследования и диагностические тест-системы in vitro. Исследование чувствительности инфекционных агентов и оценка функциональных характеристик изделий для исследования чувствительности к антимикробным средствам. Часть 1. Референтный метод лабораторного исследования активности антимикробных агентов против быстрорастущих аэробных бактерий, вызывающих инфекционные болезни. 2010.

13. Ardebili A, Lari AR, Talebi M. Correlation of ciprofloxacin resistance with the AdeABC efflux system in Acinetobacter baumannii clinical isolates. Ann Lab Med. 2014;34(6):433-438. doi: 10.3343/ alm.2014.34.6.433

14. Edelstein MV, Skleenova EN, Shevchenko OV, D'souza JW, Tapalski DV, et al. Spread of extensively resistant VIM-2 positive ST235 Pseudomonas aeruginosa in Belarus, Kazakhstan, and Russia: a longitudinal epidemiological and clinical study. Lancet Infect. Dis. 2013;13(10):867-876.

15. Zhao WH, Hu Z, Chen G, Ito R, Hu ZQ. Contributions of IMP10 metallo- $\beta$-lactamase, the outer membrane barrier and the MexAB-OprM efflux system to high level carbapenem resistance in Pseudomonas aeruginosa. Chemotherapy. 2009;55(3):168-174. doi: $10.1159 / 000217745$

16. Al-Kabsi AM, Yusof MYBM, Mansor M, Siok Yan GO, Manikam R, Sekaran SD. Multidrug efflux pumps over expression and its association with porin down regulation and $\beta$-lactamase production among nosocomial P. aeruginosa isolates from University of Malaya Medical Center, Malaysia. IJCEBS. 2015;3(2):125-135.

17. Tenover FC. Mechanisms of antimicrobial resistance in bacteria. Am J Med. 2006;119(6):3-10. doi: 10.1016/j.amjmed.2006.03.011

18. Masuda N, Sakagawa E, Ohya S, Gotoh N, Tsujimoto H, Nishino T. Substrate specificities of MexAB-OprM, MexCD-OprJ, and MexXYOprM efflux pumps in Pseudomonas aeruginosa. Antimicrob Agents Chemother. 2000;44(12):3322-3327. doi: 10.1128/ AAC.44.12.3322-3327.2000

19. Nikaido H. Antibiotic resistance caused by gram negative multidrug efflux pumps. Clin Infect Dis. 1998;27(Suppl.1):32-41.

20. Xavier DE, Picao RC, Girardello R, Fehlberg LCC, Gales AC. Efflux pumps expression and its association with porin down regulation and $\beta$-lactamase production among Pseudomonas aeruginosa causing bloodstream infections in Brazil. BMC Microbiol. 2010;10:217. doi: 10.1186/1471-2180-10-217

21. Sacha P, Michalska A, Ojdana D, Wieczorek P, Hauschild T, Majewski P, Tryniszewska E. Identification of plasmid OXA and other $\beta$-lactamase genes among carbapenem resistant isolates of Pseudomonas aeruginosa from the Clinical University Hospital in northeastern Poland. New Microbiol. 2015;38(2):271-275.

22. Li H, Luo YF, Williams BW, Blackwell TS, Xie CM. Structure and function of OprD protein in Pseudomonas aeruginosa: from antibiotic resistance to novel therapies. Int J Med Microbiol. 2012;302(2):63-68. doi: 10.1016/j.ijmm.2011.10.001

\section{КОНТАКТНАЯ ИНФОРМАЦИЯ}

Лазарева Анна Валерьевна, кандидат медицинских наук, заведующая лабораторией микробиологии Научного центра здоровья детей

Адрес: 119991, Москва, Ломоносовский пр-т, д. 2, стр. 1, тел.: +7 (499) 134-53-87, e-mail: annalaz71@mail.ru

Крыжановская Ольга Андреевна, младший научный сотрудник лаборатории микробиологии

Научного центра здоровья детей

Адрес: 119991, Москва, Ломоносовский пр-т, д. 2, стр. 1, тел.: +7 (499) 134-53-87, e-mail: o-kryzhanovskaya@yandex.ru

Бочарова Юлия Александровна, лаборант-исследователь лаборатории микробиологии

Научного центра здоровья детей

Адрес: 119991, Москва, Ломоносовский пр-т, д. 2, стр. 1, тел.: +7 (499) 134-53-87, e-mail: ivrin7@mail.ru

Чеботарь Игорь Викторович, доктор медицинских наук, ведущий научный сотрудник лаборатории микробиологии Научного центра здоровья детей

Адрес: 119991, Москва, Ломоносовский пр-т, д. 2, стр. 1, тел.: +7 (499) 134-53-87, e-mail: nizarnn@yandex.ru

Маянский Николай Андреевич, доктор медицинских наук, заведующий лабораторным отделом

Научного центра здоровья детей

Адрес: 119991, Москва, Ломоносовский пр-т, д. 2, стр. 1, тел.: +7 (499) 134-02-18, e-mail: mayansky@nczd.ru 